\title{
Vaccine Design from the Microtubules Role in Coronavirus Entry and Exit: A Molecular Dynamic and Docking Simulation
}

\author{
Farnoush Naghsh ${ }^{1}$, Majid Monajjemi ${ }^{2, *}$ (iD \\ 1 Department of Chemistry, Science and Research Branch, Islamic Azad University, Tehran, Iran \\ 2 Department of Chemical engineering, Central Tehran Branch, Islamic Azad University, Tehran, Iran \\ * Correspondence: m_monajjemi@ srbiau.ac.ir; maj.monajjemi@iauctb.ac.ir (M.M.);
}

Scopus Author ID 670181068

Received: 24.07.2021; Revised: 26.09.2021; Accepted: 30.09.2021; Published: 4.11.2021

\begin{abstract}
The accurate assembling of microtubules identifies microtubular filaments for a coronavirus that directs the site of viral. By this work, we are able to design a peptide-based multi-epitope vaccine from the surface glycoprotein inside the microtubules via molecular dynamic and docking simulation. Therefore, cell-mediated immunity can be killing the viral particles of the coronavirus. Predicted epitopes were merged using appropriate linkers to increase the immunogenicity of the vaccine. A wide range of bioinformatics analyses was accomplished based on published biological protein sequences in this study. Using molecular docking technology of Discovery-Studio 201673, the receptor-ligand docking of viral proteins with human heme (or porphyrins) was simulated.
\end{abstract}

Keywords: microtubules; vaccine design; coronavirus.

(C) 2021 by the authors. This article is an open-access article distributed under the terms and conditions of the Creative

Commons Attribution (CC BY) license (https://creativecommons.org/licenses/by/4.0/).

\section{Introduction}

\subsection{Microtubule and its biological function.}

Microtubules consist of long protein structures with a dynamic cytoskeletal of morphological changes. It has multiple functions inside the cellular processes, such as peculiar biophysical settings in the internal environment. The microtubule structures are the same as tubular polymers, while its thickness diameter is about $25 \mathrm{~nm}$, wherein the two dimers can be assembled from head to tail [1-10]. Although several microtubules are hugely excluded from the cytoplasmic in influence virus, $2.2 \mathrm{~nm}^{2}$ sidelong pores and $2.4 \mathrm{~nm}^{2}$ portals at their ends are attached to the cytoplasm section. Currently, particular particles have been explored in whole structures of microtubules which those particles can affect the other section of cell components. Although distinguishing these ingredients inside the luminal might be difficult, these molecules have culminated using the vitreous electron microscopy technique [4,6]. Moreover, an exact study of those sections can explain the tubulin-motor- proteins (TMP) mechanism, such as dynamics of assembling, transport situations, interactions among other cell ingredients, and especially virus entry and exit [5-10]. A stathmin-like domain (SLD) such as RB3 is a known protein for responding signals to the extracellular (mostly in breast cancers). It is an important inhibitor that makes a close interaction with other tubulins. Stathmin has a soluble and cytoplasmic exclusivity that plays an important role in regulating rapid microtubules reconstructing the cytoskeleton due to the cell's requirements $[8,9]$. A collection of the ribbon 
charts of $\alpha \beta$-tubulins heterodimers with Taxol components are shown in Figure 1. The guanosine triphosphate "GTPase" domain and the C-terminal domain on the external surface are shown in Figure 1, and as it can be seen, the GTP is surrounded between $\alpha$ and $\beta$ tubulins heterodimers. Whole microtubules can be screwed and bent without being located under great strain, and it can be seen in fluorescent microtubules images during growing [11-15].

During the bending of a microtubule, individual proto-filaments must be bent in several orientations; therefore, there are multiple bent situations for related dimers of each protofilament. Many attempts have been accomplished for characterization of the 3 major sections, including the first of microtubule structure, second heterodimers, and finally curved Protofilament. The establishment of the tubulins-stathmin complexes presented a new approach for stabilizing tubulins in the solution of any crystallization.

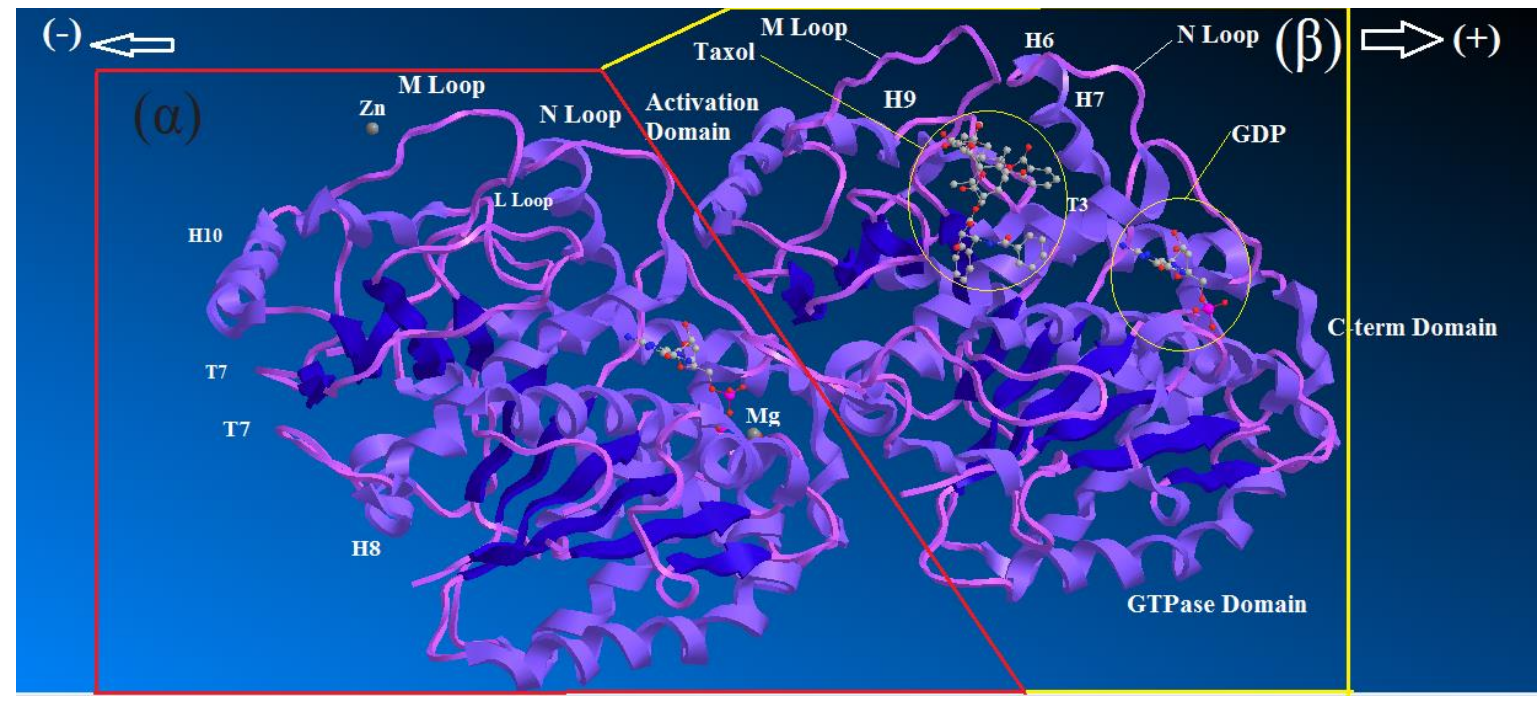

Figure 1. The $\beta$-tubulin has been hydrolyzed via GDP in the domain of $\alpha$-tubulin. Taxol is located under the coverage of $\beta$-tubulin, where is occupied by the extended L-loop.

\subsection{Microtubules role in coronavirus entry.}

Several animal viruses, including adenoviruses, influenza, and coronavirus, are related to microtubule structures [16-19]. Although the dynamic interaction among these viruses and also host cytoskeletal proteins varies largely, the microtubule structure consistently provides a concept of oriented transporting. The tubular structure undergoes reorganization following viral infections, demonstrating the tendency for invading pathogens. The microtubules contribution to the transport of coronavirus is completely evidenced by the location of microtubules. The accurate assembling of microtubules identifies microtubular filaments for a coronavirus that directs the site of viral. Microtubules facilitate virus-host interactions during covid-19 disease, especially during viral entry and exit. In eukaryotic systems, endocytosis makes the uptake of external cargo. Although a wide range of several materials, including receptor-ligand, trans-membrane proteins, phospholipids, and intracellular pathogens, are restructured via endocytosis, cellular machinery for endocytosis provide specialized microenvironments for aimed cargo transport [20]. Endosome maturation is necessary for efficient downstream cargo transition that can be transported through the endocytic route [20, 21]. By returning this cargo to the plasma membrane, a determined collection of material, including invading viruses, is attacked towards lysosomes [20]. For several viruses, including influenza and especially coronavirus, the endocytic direction is first exploited (for priming) and then will appear during the subcellular transition of viral genome replication. The cellular 
cytoskeletons of microtubules build the basic components of the endocytic machinery, which are exploited by several particles (Figure 2).

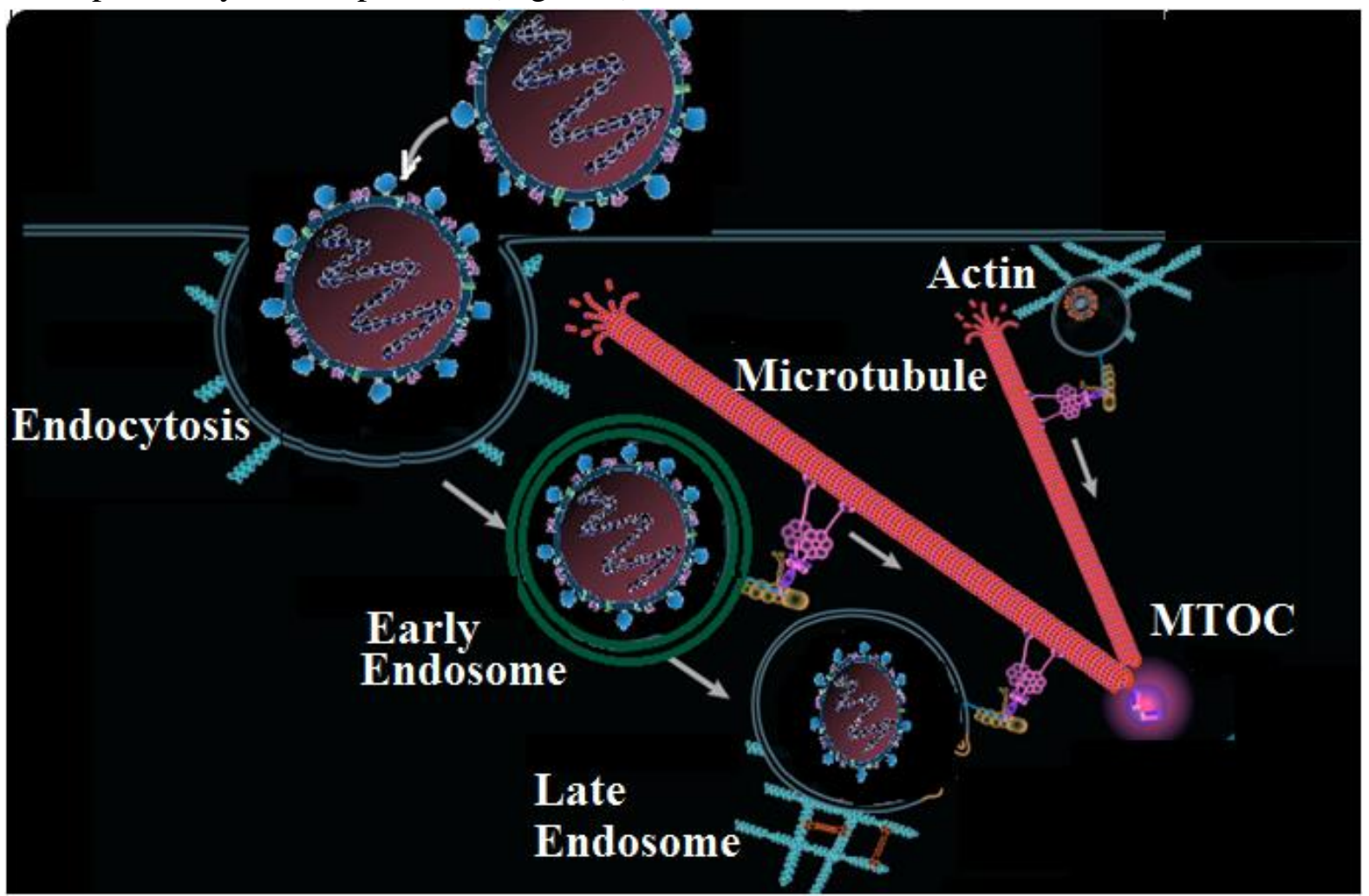

Figure 2. A schematic of coronavirus endocytosis and early transition through the cell, SSRNA is a singlestranded sense RNA. Viral particles consist of an outer envelope containing the M proteins (MP) and E proteins (EP).

Endosomes and their components interact with several actin filaments [22, 23], which, together with their associated myosin motors with a forth and back movement of EEs. Since endosomes movement to the cellular interior, therefore retrograde transport is related to microtubules and their related dynein motors [24, 25]. This machinery has the ability to straightforward transport macromolecules to the appropriate cellular segments.

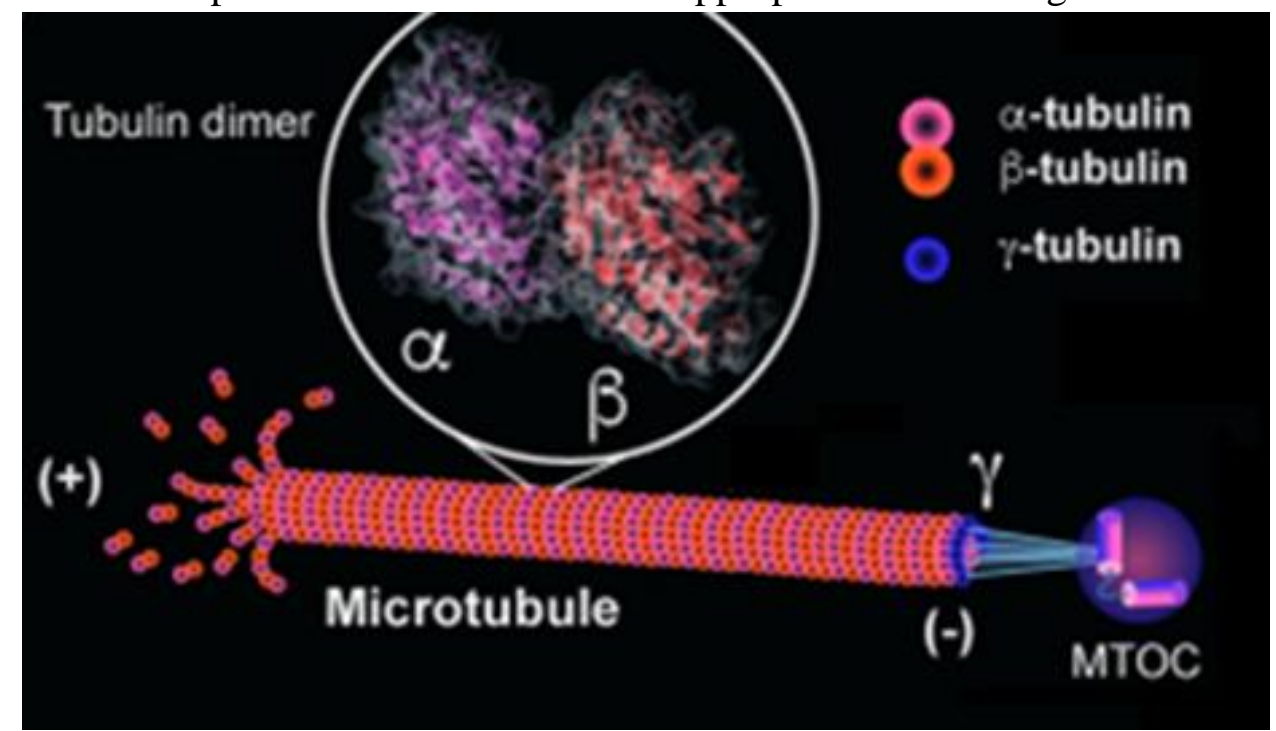

Figure 3. Structure of microtubules. (A) Microtubule filaments are comprised of multiple dimer complexes of $\alpha$ - and $\beta$-tubulin assembled around a hollow core. (B) Microtubules form dynamic networks in the cytoplasm.

Endosome sorting is mostly related to sorting proteins, which have interacted with microtubule motors and mediate endosome-microtubule interactions, subcellular transition, 
and localization [26]. The fluorescent studies of individual coronavirus, including quantumdot-and viral tracking techniques, have been accomplished for microtubules during transit through the cytoplasm (Figure 3).

Moreover, to help the targeted transport of any ingredients direct to the cellular interior, also provide specialized subunits microenvironments that allow for the suitable replication of coronavirus. Endocytic vesicles are separated from the surrounding cytosol by the phospholipids $\mathrm{m}$. While cytosolic $\mathrm{pH}$ generally appears at around 7.45, ATP-related proton pumps in the membrane, within the range of acidic $\mathrm{pH}$ levels ( $\mathrm{pH} 6.4-4.2)$ within optimization the catalytic activities of several enzymes [27-31].

For coronavirus, the progressive acidification during movement towards the nucleus represents downstream viral replication. In addition, microtubule de-polymerization exhibited a consistent ability for dealing with the maturation of endocytic vesicles [32].

\subsection{Microtubules in Coronavirus Egress.}

The genome replication, coronavirus can be transited to the cytoplasm and egress to the plasma membrane for virion assembly. Nuclear export requires the assembly of a nuclear export complex containing nucleoproteins. This complex mediates the association of exportin1/XPO1/CRM1 with vRNPs and the translocation of viral proteins from the nucleus to the cytoplasm [33]. The magnitude pores through increased activation coronavirus infected cells. Coronavirus induced the maturation in infected cells, which led to cholesterol enrichment along with the microtubule.

\section{Materials and Methods}

\subsection{Vaccine designing from the glycoprotein epitopes of COVID-19.}

Novel strategies of the immune informatics approach were applied to investigate the multi-epitope-based vaccine (Figure 4). The amino acid sequence (around 1300 amino acids) of the surface glycoprotein coronaviruses were recovered from NCBI. For vaccines, the surface diagrams of the glycoprotein were selected to distinguish the immunogenic identity for the vaccine produced. Definition of immunogenic T-Cells or MHC-I and II was accomplished via applying the Immune Epitopes Database (IEDB) (https://www.iedb.org) [34]. It employed a different prediction pathway for epitope binding analysis (Figure 4). MHC class I and II molecules were predicted via the Stabilized Matrix Method (SMM) accounting and neutralnetwork-based tool (net MHC-1.1) [35-37]. Epitopes were regulated from the predicted ensemble (IC50 $\leq 250 \mathrm{nM}$ ), and also B-Cell immunogenic was designed using BCPRED (http://ailab.cs.iastate.edu/bcpreds). The B \& T-cells epitopes are immune-dominant and sensitive to increasing neutralizing-antibody. B-cell epitopes are indispensable for epitopebased vaccine design and development [38]. The surface of proteins can be encoded by MHC where are vital for the adaptive immune system, containing MHC-II binding interferoninducing epitopes (Figure 4). For the determination of antigenicity, allergenicity, and their toxicity of the prepared vaccine software has been applied (Vaxijen Version 2.0) [39]. An online server (http://crdd.osdd./net/raghava/algpred/) was applied to identify the allergenicity of the constructs with a -0.5 threshold amount [40]. Expasy Protparam (https://web.expasy.org/protparam/) were applied for predicting physical chemistry data such as amino acid structure, molecular weight, estimated half-life, aliphatic item, hydrophobicity, aromaticity, and instability index of the vaccine. 


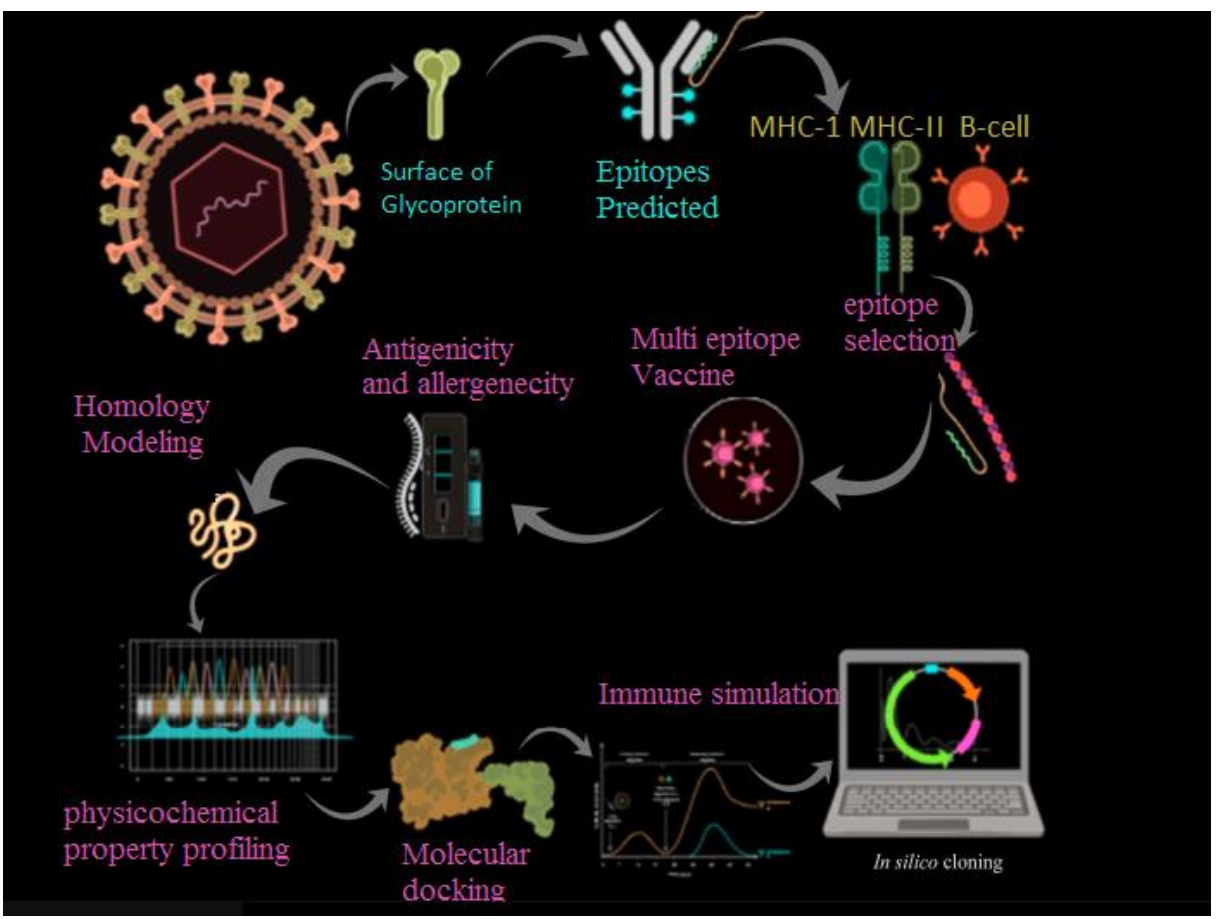

Figure 4. Schematic workflow followed for the multi-epitope vaccine design.

\subsection{Molecular docking and MD simulation.}

For docking simulation, iGEM-DOCK software has been applied. Hereby, an acceptable receptor can be defined for the binding site in whole coronavirus structures. The mRNA structure is worked with a ligand of the virus, and iGEM-DOCK can help to define the suitable binding site quickly. Following steps were accomplished in docking: (a), Providing binding site on the ligands. (b) Browsing the files. (c) Defining the binding site type. (d) Defining the center of the binding location. (e) Defining the size of the space and radius for ligands. IGEM-DOCK yields an analysis surrounding visualized tools and post-analysis tools for users to visualize the docked states and categories through the protein-ligand interactions. IGEM-DOCK clusters the ligands corresponding to interaction composition features extracted from the protein-ligand interactions with related composition. The data in subsets will share some general properties. These are based on interaction and atomic combination aspects. Interaction aspects are extracted from the protein-ligand couples, and atomic combinations are calculated atomic types in various functional groups [41, 42]. TLR7/8 complex (TLR8 PDB ID:3w3g) was downloaded from Protein Databank (PDB) (https://www. rcsb.org). FireDock refines and re-scoring the docked complexes and ranks the complexes based on binding score and global binding energy [43]. Our results have been discussed based on our previous works [45-66].

\section{Results and Discussion}

\subsection{Genetic defecting and disordering.}

Defecting due to genetic mutations changes the mRNA and causes dangerous metabolic irregularity, which mostly appears in early childhood and destroys the tissues. Mutations in those complexes are consequent in alternative functionalities of several assembling, and each mutation is associated with the etiologies of the specific disease within some symbolization in several disorders. 
A wide range of bioinformatics analyses was accomplished based on published biological protein sequences in this study. Using molecular docking technology (LibDock tool) of Discovery-Studio 201673, the receptor-ligand docking of viral proteins with human heme (or porphyrins) was simulated. Depending on the results of the bioinformatics analysis, the related molecular of the disease was proposed. It can be discussed about the polar and charged residues for many of the fraction and binding interfaces of CoV2-RBD and the ACE2. Moreover, electrostatic interaction has critical points for a complex formation. Distances among the two mentioned proteins are a key at the binding interfaces identified and summarized in Table 1 for the three representative models (Figure $5 \&$ Table 1).

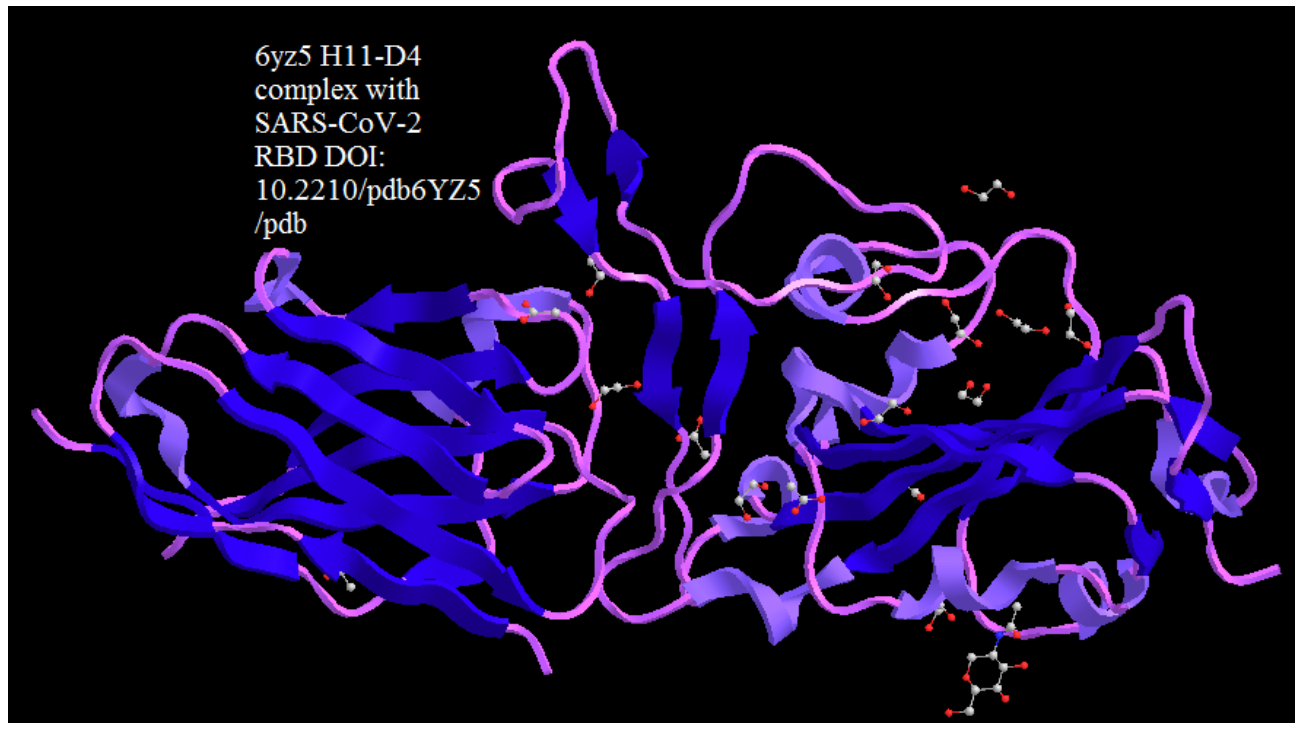

Figure 5. Severe acute respiratory syndrome, coronavirus 2, Lama glama.

The majority of those residues are preserved for models. The same simulations can be accomplished for the SARS-RBD/ACE2 complexes. Interestingly, in related simulations, the SARS-RBD counterpart in CoV2-RBD did not form near contacts with the ACE(2).

The hydrogen bonds among the CoV2-RBD and ACE2 can be extracted using VMD program. It can be discussed that the number of hydrogen bonds fluctuated over time.

Similar trends can be observed in the other simulations, suggesting that the binding became stronger as the simulation progressed. Some extra program such as the noisy software (http://www.bioinf.uni-leipzig.de/Software/noisy/) has also been applied for this work [67-73].

Table 1. Anti-SARS-CoV-2 S protein RBD neutralizing antibody and Nucleo-capsid antibody extracted from SSRNA in related microtubules.

\begin{tabular}{|c|c|c|c|}
\hline Molecule & Cat. No. & Species & Product Description \\
\hline & $\mathrm{AC} 2(\mathrm{R} 5246)$ & Rat & Rat ACE2 / ACEH Protein, His Tag \\
\hline & AC2(M5248) & Mouse & Mouse ACE2 / ACEH Protein, His \\
\hline & AC2(P5248) & $\begin{array}{l}\text { Paguma } \\
\text { larvata }\end{array}$ & Paguma larvata ACE2 / ACEH Protein, His \\
\hline \multirow{6}{*}{$\begin{array}{l}\text { Nucleocaps } \\
\text { id protein }\end{array}$} & NUN(V52H3) & HCoV-OC43 & HCoV-OC43 Nucleocapsid protein, His Tag \\
\hline & SPN(S52H5) & SARS & SARS S protein (R667A), His Tag \\
\hline & $\mathrm{S} 1 \mathrm{~N}(\mathrm{C} 52 \mathrm{H} 4)$ & SARS-CoV-2 & SARS-CoV-2 (COVID-19) S1 protein, \\
\hline & $\mathrm{S} 1 \mathrm{~N}(\mathrm{C} 5255)$ & SARS-CoV-2 & SARS-CoV-2 (COVID-19) S1 protein \\
\hline & $\mathrm{S} 1 \mathrm{~N}(\mathrm{C} 5257)$ & SARS-CoV-2 & SARS-CoV-2 (COVID-19) S1 protein, Mouse IgG2a \\
\hline & S1N(C5256) & SARS-CoV-2 & 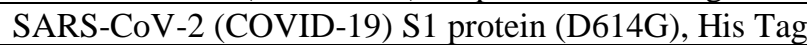 \\
\hline \multirow{2}{*}{$\begin{array}{l}\text { S2 protein } \\
\text { S protein } \\
\text { RBD }\end{array}$} & $\mathrm{S} 2 \mathrm{~N}(\mathrm{C} 52 \mathrm{H} 5)$ & SARS-CoV-2 & SARS-CoV-2 (COVID-19) S2 protein, His Tag \\
\hline & $\operatorname{SPD}(\mathrm{C} 82 \mathrm{E} 9)$ & SARS-CoV-2 & $\begin{array}{c}\text { Biotinylated SARS-CoV-2 (COVID-19) S protein RBD, } \\
\text { His,AvitagTM (MALS verified) }\end{array}$ \\
\hline
\end{tabular}




\begin{tabular}{|c|c|c|c|}
\hline Molecule & Cat. No. & Species & Product Description \\
\hline & SPDC5255 & SARS-CoV-2 & $\begin{array}{c}\text { SARS-CoV-2 (COVID-19) S protein RBD, Fc Tag (MALS } \\
\text { verified) }\end{array}$ \\
\hline & SPDS52H6 & SARS & SARS S protein RBD, His Tag (MALS verified) \\
\hline & SPDC52H3 & SARS-CoV-2 & $\begin{array}{c}\text { SARS-CoV-2 (COVID-19) S protein RBD, His Tag (MALS } \\
\text { verified) }\end{array}$ \\
\hline & SPDC5259 & SARS-CoV-2 & $\begin{array}{c}\text { SARS-CoV-2 (COVID-19) S protein RBD, Mouse IgG2a Fc } \\
\text { Tag }\end{array}$ \\
\hline & SPDS52H4 & SARS-CoV-2 & SARS-CoV-2 (COVID-19) S protein RBD (V367F), His Tag \\
\hline & SPDS52H5 & SARS-CoV-2 & $\begin{array}{c}\text { SARS-CoV-2 (COVID-19) S protein RBD (N354D), His } \\
\text { Tag }\end{array}$ \\
\hline & SPD-S52H3 & SARS-CoV-2 & $\begin{array}{c}\text { SARS-CoV-2 (COVID-19) S protein RBD (N354D, } \\
\text { D364Y), His Tag }\end{array}$ \\
\hline & SPD-C52H4 & SARS-CoV-2 & SARS-CoV-2 (COVID-19) S protein RBD (G476S), His Tag \\
\hline & SPDC52H5 & SARS-CoV-2 & $\begin{array}{c}\text { SARS-CoV-2 (COVID-19) S protein RBD (V483A), His } \\
\text { Tag }\end{array}$ \\
\hline $\begin{array}{l}\text { S1 protein } \\
\text { CTD }\end{array}$ & S1DC52H3 & SARS-CoV-2 & SARS-CoV-2 (COVID-19) S1 protein CTD, His Tag \\
\hline \multirow{2}{*}{ S protein } & SPNC52H4 & SARS-CoV-2 & $\begin{array}{c}\text { SARS-CoV-2 (COVID-19) S protein (R683A, R685A), His } \\
\text { Tag }\end{array}$ \\
\hline & SPNC52H8 & SARS-CoV-2 & SARS-CoV-2 (COVID-19) S protein (R683A, R685A), His \\
\hline \multirow[t]{3}{*}{$\begin{array}{l}\text { Envelope } \\
\text { protein }\end{array}$} & ENNC5128 & SARS-CoV-2 & SARS-CoV-2 (COVID-19) Envelope protein, His Tag \\
\hline & NUNC5227 & SARS-CoV-2 & SARS-CoV-2 (COVID-19) Nucleocapsid protein, His Tag \\
\hline & NUNC81Q6 & SARS-CoV-2 & Biotinylated SARS-CoV-2 (COVID-19) Nucleocapsid \\
\hline $\begin{array}{l}\text { NSP7 } \\
\text { NSP8 }\end{array}$ & NS8C5125 & SARS-CoV-2 & SARS-CoV-2 (COVID-19) NSP7\&NSP8 Protein, His Tag \\
\hline $\begin{array}{l}\text { NSP16 } \\
\text { NSP10 }\end{array}$ & NS0C51W3 & SARS-CoV-2 & SARS-CoV-2 (COVID-19) NSP16\&NSP10 Heterodimer \\
\hline
\end{tabular}

Based on items in Table 1, four different categories have been selected as names: AC2(R5246), SPN(S52H5), NUNC81Q6, and NS0C51W3. Therefore four different constructs were built by this integration of linkers.

The sequence of these constructs differed from each other according to the adjuvant used and the arrangement order of the constituent segments. The linker "EAAAK" (blue) links the adjuvant (black) in the constructs. The GGGS and HEYGAEALERAG (grey) link the epitopes. Immunogenic epitopes (red) and the immune enhancer adjuvant, PADRE, as well as linker sequences, were inserted as follows:

Number (1)

ALATVNDLIANLRERAEETRAETRTRVEERRARLTKFQEDLPEQFIELRDKFTTEELRKAAEGYLEAATNRYNEL QTRAVGERAAKLVGIELEAAAKAKFVAAWTLKAAAGGGSGDEVRQIAPGQTGKIADYNYKGGGSSYQTQTN SPRRARSVASQSGGGSAKFVAAWTLKAAAGGGSILPDPSKPSKRSFIEDLLFNKVHEYGAEALERAGQCVNLT TRTQLPPAYTNSFTRGV

Number(2)

CRVRGGRCAVLSCLPKEEQIGKCSTRGRKCCRRKKEAAAKAKFVAAWTLKAAGDEVRQIAPGQTGKIADYNYKGGGSILPDPSKP SKRSFIEDLLFNKVGGGSAKFVAAWTLKAAAGGGSSYQTQTNSPRRARSVASQSHEYGAEALERAGQCVNLTTRTQLPPAYT

Number(3)

NIDDIKAPLLAALGAADLALATVNELITNLRERAEETRRSRVEESRARLEKFTAEELRKAAEGYLEAATSELVERGEAALERLRSQQ SFEEVSARAEGYVDQAVELTQEALGTVASQVEGRAAAAWTLKAAAGGGSSYQTQTNSPRRARSVASQSGGGSQCVNLTTRTQTR GVGGGSAKFVAAWTLKAAAGGGS GDEVRQIAPGQTGKIADYNYKHEYGAEALERAGILPDPSKPSKRSFIEDLLFNKVHEYGAEA LERAGAKF

Number(4)

AAAPVAVAAAGAAPAGAAVEAAEEQSEFDVILEAAGDVVREIVSGLGLKEAKDLVDGAPKPLAKLEAAGATVAWTLKAAAGGG SQCVNLTTRTQLPPAYTNSFTRGVGGGSGDEVRQIAPGQTGKIADYNYKGGGSAKFVAAWTLKAAAGGGSILPDPSKPSKRSFIED LLFNKVHEYGAEALERAGSYQTQTNSPRRA

All the four vaccines prepared were tested for allergenicity, antigenicity, and Algpred server, Vexijen v2.0 [44] in Table 2. 
Table 2. Antigenicity and allergenicity of the various vaccine constructs.

\begin{tabular}{c|c|c} 
Item & $\begin{array}{c}\text { Antigenicity } \\
\text { (Threshold > 0.5) }\end{array}$ & Allergenicity \\
\hline 1 & 0.4656 & -0.875854 \\
\hline 2 & 0.4213 & -0.786857 \\
\hline 3 & 0.3954 & -0.564778 \\
\hline 4 & 0.4098 & -0.456788
\end{tabular}

The most antigenic vaccine construct, and least allergenic were selected as suitable vaccines to elicit host immune response. Physiochemical properties of all vaccine constructs were predicted via the Prot-Param server, as shown in Table 3.

Table 3. Physical chemistry data of the vaccine constructs.

\begin{tabular}{c|c|c|c|c} 
Item & Number of amino acids & Theoretical PI & Aliphatic index & Instability index \\
\hline 1 & 295 & 7.55 & 69.45 & 31.25 (stable) \\
\hline 2 & 165 & 8.45 & 71.23 & 29.43 (stable) \\
\hline 3 & 255 & 8.23 & 69.55 & 33.56 (stable) \\
\hline 4 & 183 & 4.55 & 80.44 & 55.44 (unstable)
\end{tabular}

Potentially, vaccines must be able to bind to different HLA allelic proportions of the human population, where it is the most considerable property for its proper function inside the host. The docking of all above vaccines structures was accomplished with TLR7, TLR8, and TLR 4/MD2 complexes. After analyzing all vaccine stabilities, we manufacture the structure based on different physical chemistry properties and docking scores.

The results of the docking simulation are shown in Table 4. Therefore, we selected number 2, as a suitable vaccine against the 2019 novel Coronavirus (2019-nCoV). In addition, molecular docking of the vaccines was performed with the modeled TLR7 using the HADDOCK web server.

Table 4. Global, Attractive and Repulsive Energies for four items

\begin{tabular}{c|c|c|c} 
Item & $\begin{array}{c}\text { Global Energy } \\
\text { (Kcal/mol) }\end{array}$ & $\begin{array}{c}\text { Attractive } \\
\text { VdW }\end{array}$ & $\begin{array}{c}\text { Repulsive } \\
\text { VdW }\end{array}$ \\
\hline 1 & -40.44 & -35.66 & 18.77 \\
\hline 2 & -70.55 & -43.34 & 15.44 \\
\hline 3 & -50.34 & -29.66 & 17.56 \\
\hline 4 & -39.44 & -21.33 & 20.44
\end{tabular}

\section{Conclusions}

The immune simulation showed an enhanced antibody after virtual administration. It also exhibits that the microtubule and their tubulins have an important role in healthy immune response elicitation. The final and suitable vaccine structure might also be tested in vitro.

\section{Funding}

This research received no external funding.

\section{Conflicts of Interest}

The authors declare no conflict of interest.

\section{References}

1. Prosser, S.L.; Pelletier, L. Mitotic spindle assembly in animal cells: A fine balancing act. Nat. Rev. Mol. Cell. Biol. 2017, 18, 187-201, https://doi.org/10.1038/nrm.2016.162. 
2. Chaaban, S.; Brouhard, G.J. A microtubule bestiary: structural diversity in tubulin polymers. Mol. Biol. Cell. 2017, 28, 2924-2931, https://doi.org/10.1091/mbc.e16-05-0271.

3. Janke, C.; Magiera, M.M. The tubulin code and its role in controlling microtubule properties and functions. Nat. Rev. Mol. Cell. Biol. 2020, 21, 307-326, https://doi.org/10.1038/s41580-020-0214-3.

4. Akhmanova, A.; Steinmetz, M.O. Microtubule minus-end regulation at a glance. J. Cell. Sci. 2019, 132, 1-7, https://doi.org/10.1242/jcs.227850.

5. Tovey, C.A.; Conduit, P.T. Microtubule nucleation by $\gamma$-tubulin complexes and beyond. Essays Biochem 2018, 62, 765-780, https://doi.org/10.1042/ebc20180028.

6. Thawani, A.; Kadzik, R.S.; Petry, S. XMAP215 is a microtubule nucleation factor that functions synergistically with the $\gamma$-tubulin ring complex. Nat. Cell Biol. 2018, 20, 575-585, https://doi.org/10.1038/s41556-018-0091-6.

7. Luders, J. XMAP215 joins microtubule nucleation team. Nat. Cell. Biol. 2018, 20, 508-510, https://doi.org/10.1038/s41556-018-0100-9.

8. Woodruff, J.B.; Ferreira Gomes, B.; Widlund, P.O.; Mahamid, J.; Honigmann, A.; Hyman, A.A. The Centrosome Is a Selective Condensate that Nucleates Microtubules by Concentrating Tubulin. Cell 2017, 169, 1066-1077.E10, https://doi.org/10.1016/j.cell.2017.05.028.

9. Vemu, A.; Atherton, J.; Spector, J.O.; Moores, C.A.; Roll-Mecak, A. Tubulin isoform composition tunes microtubule dynamics. Mol. Biol. Cell 2017, 28, 3564-3572, https://doi.org/10.1091/mbc.e17-02-0124.

10. Yates, B.; Braschi, B.; Gray, K.A.; Seal, R.L.; Tweedie, S.; Bruford, E.A. Genenames.org: the HGNC and VGNC resources in 2017. Nucleic Acids Research 2017, 45, D619-D625, https://doi.org/10.1093/nar/gkw1033.

11. Shin, S.C.; Im, S-K.; Jang, E-H.; Jin, K.S.; Hur, E-M.; Kim, E.E. Structural and Molecular Basis for Katanin Mediated Severing of Glutamylated Microtubules. Cell Reports 2019, 26, 1357-1367, E5, https://doi.org/10.1016/j.celrep.2019.01.020.

12. Guild, J.; Ginzberg, M.B.; Hueschen, C.L.; Mitchison, T.J.; Dumont, S. Increased lateral microtubule contact at the cell cortex is sufficient to drive mammalian spindle elongation. Mol. Biol. Cell, 2017, 28, 1975-1983, https://doi.org/10.1091/mbc.e17-03-0171.

13. Gillard, G.; Roper, K. Control of cell shape during epithelial morphogenesis: recent advances. Curr. Opin. Gen\&Dev. 2020, 63, 1-8, https://doi.org/10.1016/j.gde.2020.01.003.

14. Dogterom, M.; Koenderink, G.H. Actin-microtubule crosstalk in cell biology. Nat. Rev. Mol. Cell Biol. 2019, 20, 38-54, https://doi.org/10.1038/s41580-018-0067-1.

15. Burute, M.; Kapitein, L.C. Cellular Logistics: Unraveling the Interplay Between Microtubule Organization and Intracellular Transport. Annual Rev. Cell Dev. Biol. 2019, 35, 29-54, https://doi.org/10.1146/annurevcellbio-100818-125149.

16. Greber, U.F.; Way, M. A. Superhighway to Virus Infection. Cell, 2006, 124, 741-754, https://doi.org/10.1016/j.cell.2006.02.018.

17. Dohner, K.; Nagel, C.H.; Sodeik, B. Viral stop-and-go along microtubules: taking a ride with dynein and kinesins. Trends Microbiol. 2005, 13, 320-327, https://doi.org/10.1016/j.tim.2005.05.010.

18. Radtke, K.; Dohner, K.; Sodeik, B. Viral interactions with the cytoskeleton: A hitchhiker's guide to the cell. Cell. Microbiol. 2006, 8, 387-400, https://doi.org/10.1111/j.1462-5822.2005.00679.x.

19. Smith, A.E.; Helenius, A. How viruses enter animal cells. Science, 2004, 304, 237-242, https://doi.org/10.1126/science.1094823.

20. Huotari, J.; Helenius, A. Endosome maturation. EMBO J. 2011, 30, 3481-3500, https://doi.org/10.1038/emboj.2011.286.

21. Shigematsu, H.; Imasaki, T.; Doki, C.; Sumi, T.; Aoki, M.; Uchikubo-Kamo, T.; Sakamoto, A.; Tokuraku, K.; Shirouzu, M.; Nitta, R. Structural insight into microtubule stabilization and kinesin inhibition by Tau family MAPs. J. Cell Biol. 2018, 217, 4155-4163, https://doi.org/10.1083/jcb.201711182.

22. Granger, E.; McNee, G.; Allan, V.; Woodman, P. The role of the cytoskeleton and molecular motors in endosomal dynamics. Semin. Cell Dev. Biol. 2014, 31, 20-29, https://doi.org/10.1016/j.semcdb.2014.04.011.

23. Zhang, L-J.; Xia, L.; Liu, S-L.; Sun, E-Z.; Wu, Q-M.; Wen, L.; Zhang, Z-L.; Pang, D-W. A "Driver Switchover" Mechanism of Influenza Virus Transport from Microfilaments to Microtubules. ACS Nano 2018, 12, 474-484, https://doi.org/10.1021/acsnano.7b06926.

24. Murray, J.W.; Bananis, E.; Wolkof, A.W. Reconstitution of ATP-dependent Movement of Endocytic Vesicles Along Microtubules In Vitro: An Oscillatory Bidirectional Process. Mol. Biol. Cell 2000, 11, 419-433, https://doi.org/10.1091/mbc.11.2.419. 
25. Bomsel, M.; Parton, R.; Kuznetsov, S.A.; Schroer, T.A.; Gruenberg, J. Microtubule- and motor-dependent fusion in vitro between apical and basolateral endocytic vesicles from MDCK cells. Cell 1990, 62, 719-731, https://doi.org/10.1016/0092-8674(90)90117-W.

26. Hunt, S.D.; Townley, A.K.; Danson, C.M.; Cullen, P.J.; Stephens, D.J. Microtubule motors mediate endosomal sorting by maintaining functional domain organization. J. Cell Sci. 2013, 126, 2493-2501, https://doi.org/10.1242/jcs.122317.

27. Maxson, M.E.; Grinstein, S. The vacuolar-type $\mathrm{H}^{+}$-ATPase at a glance - more than a proton pump. J. Cell Sci. 2014, 127, 4987-4993, https://doi.org/10.1242/jcs. 158550.

28. Nishi, T.; Forgac, M. The vacuolar $\left(\mathrm{H}^{+}\right)$-ATPases-nature's most versatile proton pumps. Nat. Rev. Mol. Cell Biol. 2002, 3, 94-103, https://doi.org/10.1038/nrm729.

29. Marshansky, V.; Rubinstein, J.L.; Gruber, G. Eukaryotic V-ATPase: novel structural findings and functional insights. Biochim. Biophys. Acta 2014, 1837, 857-879, https://doi.org/10.1016/j.bbabio.2014.01.018.

30. Maxfield, F.R.; McGraw, T.E. Endocytic recycling. Nat. Rev. Mol. Cell Biol. 2004, 5, 121-132, https://doi.org/10.1038/nrm1315.

31. Pungercar, J.R.; Caglic, D.; Sajid, M.; Dolinar, M.; Vasiljeva, O.; Pozgan, U.; Turk, D.; Bogyo, M.; Turk, V.; Turk, B. Autocatalytic processing of procathepsin B is triggered by proenzyme activity. FEBS J. 2009, 276, 660-668, https://doi.org/10.1111/j.1742-4658.2008.06815.x.

32. Vonderheit, A.; Helenius, A. Rab7 associates with early endosomes to mediate sorting and transport of Semliki forest virus to late endosomes. PLoS Biol. 2005, 3, e233, https://doi.org/10.1371/journal.pbio.0030233.

33. Huang, S.; Chen, J.; Chen, Q.; Wang, H.; Yao, Y.; Chen, J.; Chen, Z. A second CRM1-dependent nuclear export signal in the influenza A virus NS2 protein contributes to the nuclear export of viral ribonucleoproteins. J. Virol. 2013, 87, 767-778, https://doi.org/10.1128/JVI.06519-11.

34. Shey, R.A.; Ghogomu, S.M.; Esoh, K.K.; Nebangwa, N.D.; Shintouo, C.M.; Nongley, N.F.; Asa, B.F.; Ngale, F.N.; Vanhamme, L.; Souopgui, J. In-silico design of a multi-epitope vaccine candidate against onchocerciasis and related filarial diseases. Sci. Rep. 2019, 9, 1-18, /10.1038/s41598-019-40833-X.

35. Fleri, W.; Paul, S.; Dhanda, S.K.; Mahajan, S.; Xu, X.; Peters, B.; Sette, A. The immune epitope database and analysis resource in epitope discovery and synthetic vaccine design. Front. Immunol. 2017, 8, 278, https://doi.org/10.3389/fimmu.2017.00278.

36. Wang, P.; Sidney, J.; Dow, C.; Mothé, B.; Sette, A.; Peters, B. A Systematic Assessment of MHC Class II Peptide Binding Predictions and Evaluation of a Consensus Approach. PLoS Comput. Biol. 2008, 4, e1000048, https://doi.org/10.1371/journal.pcbi.1000048.

37. Kim, Y.; Ponomarenko, J.; Zhu, Z.; Tamang, D.; Wang, P.; Greenbaum, J.; Lundegaard, C.; Sette, A.; Lund, O.; Bourne, P.E.; Nielsen, M.; Peters, B. Immune epitope database analysis resource. Nucleic Acids Res. 2012, 40, W525-W530, https://doi.org/10.1093/nar/gks438.

38. Hajighahramani, N.; Nezafat, N.; Eslami, M.; Negahdaripour, M.; Rahmatabadi, S.S.; Ghasemi, Y. Immunoinformatics analysis and in silico designing of a novel multi-epitope peptide vaccine against Staphylococcus aureus. Infect. Genet. Evol. 2017, 48, 83-94, https://doi.org/10.1016/j.meegid.2016.12.010.

39. Solanki, V.; Tiwari, V. Subtractive proteomics to identify novel drug targets and reverse vaccinology for the development of chimeric vaccine against Acinetobacter baumannii. Sci. Rep. 2018, 8, https://doi.org/10.1038/s41598-018-26689-7.

40. Doytchinova, I.; Flower, D.R. Bioinformatic approach for identifying parasite and fungal candidate subunit vaccines. Open Vaccine J. 2008, 1, 22-26, https://doi.org/10.2174/1875035400801010022.

41. Yang J-M., Chen C-C., GEMDOCK: a generic evolutionary method for molecular docking. Proteins 2004, 55, 288-304, https://doi.org/10.1002/prot.20035.

42. Yang J-M., Development and evaluation of a generic evolutionary method for protein-ligand docking. Journal of Computational Chemistry 2004, 25, 843-857, https://doi.org/10.1002/jcc.20013.

43. Muhammad, I.; Rahman, N.; Nayab, G.E.; Niaz, S.; Shah, M.; Afridi, S.G.; Khan, H.; Daglia, M.; Capanoglu, E. The Molecular Docking of Flavonoids Isolated from Daucus carota as a Dual Inhibitor of MDM2 and MDMX. Recent Pat Anticancer Drug Discov. 2020, 15, 154-164, https://doi.org/10.2174/1574892815666200226112506.

44. Grote, A.; Hiller, K.; Scheer, M.; Münch, R.; Nörtemann, B.; Hempel, D.C.; Jahn, D. JCat: A novel tool to adapt codon usage of a target gene to its potential expression host. Nucleic Acids Res. 2005, 33, W526-31, https://doi.org/10.1093/nar/gki376. 
45. Monajjemi, M. Cell membrane causes the lipid bilayers to behave as variable capacitors: A resonance with self-induction of helical proteins. Biophysical Chemistry 2015, 207, 114-127, https://doi.org/10.1016/j.bpc.2015.10.003.

46. Monajjemi, M. Liquid-phase exfoliation (LPE) of graphite towards graphene: An ab initio study. Journal of Molecular Liquids, 2017, 230, 461-472, https://doi.org/10.1016/j.molliq.2017.01.044.

47. Monajjemi, M.; Naderi, F.; Mollaamin, F.; Khaleghian, M. Drug design outlook by calculation of second virial coefficient as a nano study. Journal of the Mexican Chemical Society 2012, 56, 207-211, https://doi.org/10.29356/jmcs.v56i2.323.

48. Monajjemi, M.; Bagheri, S.; Moosavi, M.S. Symmetry breaking of $\mathrm{B}_{2} \mathrm{~N}^{(-, 0,+)}$ : An aspect of the electric potential and atomic charges. Molecules 2015, 20, 21636-21657, https://doi.org/10.3390/molecules201219769.

49. Monajjemi, M.; Mohammadian, N.T. S-NICS: An aromaticity criterion for nano molecules. Journal of Computational and Theoretical Nanoscience 2015, 12, 4895-4914, https://doi.org/10.1166/jctn.2015.4458.

50. Monajjemi, M.; Ketabi, S.; Hashemian, Z.M.; Amiri, A. Simulation of DNA bases in water: Comparison of the Monte Carlo algorithm with molecular mechanics force fields. Biochemistry (Moscow) 2006, 71, S1-8, https://doi.org/10.1134/s0006297906130013.

51. Monajjemi, M.; Lee, V.S.; Khaleghian, M.; Honarparvar, B.; Mollaamin, F. Theoretical Description of Electromagnetic Nonbonded Interactions of Radical, Cationic, and Anionic $\mathrm{NH}_{2} \mathrm{BHNBHNH}_{2}$ Inside of the $\mathrm{B}_{18} \mathrm{~N}_{18}$ Nanoring. J. Phys. Chem C 2010, 114, 15315-15330, https://doi.org/10.1021 /jp104274z.

52. Monajjemi, M.; Boggs, J.E. A New Generation of $\mathrm{B}_{\mathrm{n}} \mathrm{N}_{\mathrm{n}}$ Rings as a Supplement to Boron Nitride Tubes and Cages. J. Phys. Chem. A 2013, 117, 1670-1684, http://dx.doi.org/10.1021/jp312073q.

53. Monajjemi, M. Non bonded interaction between $\mathrm{B}_{\mathrm{n}} \mathrm{N}_{\mathrm{n}}$ (stator) and $\mathrm{BN}^{(-, 0,+)} \mathrm{B}$ (rotor) systems: A quantum rotation in IR region. Chemical Physics 2013, 425, 29-45, https://doi.org/10.1016/j.chemphys.2013.07.014.

54. Monajjemi, M.; Robert, W.J.; Boggs, J.E. NMR contour maps as a new parameter of carboxyl's OH groups in amino acids recognition: A reason of tRNA-amino acid conjugation. Chemical Physics 2014, 433, 1-11, https://doi.org/10.1016/j.chemphys.2014.01.017.

55. Monajjemi, M. Quantum investigation of non-bonded interaction between the $\mathrm{B}_{15} \mathrm{~N}_{15}$ ring and $\mathrm{BH}_{2} \mathrm{NBH}_{2}$ (radical, cation, and anion) systems: a nano molecularmotor. Struct Chem 2012, 23, 551-580, https://doi.org/10.1007/S11224-011-9895-8.

56. Monajjemi, M. Metal-doped graphene layers composed with boron nitride-graphene as an insulator: a nanocapacitor. Journal of Molecular Modeling 2014, 20, 2507, https://doi.org/10.1007/s00894-014-2507-y.

57. Monajjemi, M.; Heshmat, M.; Haeri, H.H.; Kaveh, F. Theoretical study of vitamin properties from combined QM-MM methods: Comparison of chemical shifts and energy. Russian Journal of Physical Chemistry 2006, 80, 1061-1068, https://doi.org/10.1134/S0036024406070119.

58. Monajjemi, M.; Honaparvar, B.; Khalili Hadad, B.; Ilkhani, A.; Mollaamin, F. Thermo-Chemical Investigation and NBO Analysis of Some anxileotic as Nano- Drugs. African Journal of Pharmacy and Pharmacology 2010, 4, 521-529, https://doi.org/10.33263/BRIAC106.66956705.

59. Monajjemi, M.; Najafpour, J.; Mollaamin, F. (3,3) $)_{4}$ Armchair carbon nanotube in connection with PNP and NPN junctions: Ab Initio and DFT-based studies. Fullerenes, Nanotubes and Carbon Nanostructures 2013, 21, 213-232, https://doi.org/10.1080/1536383X.2011.597010.

60. Monajjemi, M.; Jafari Azan, M.; Mollaamin, F. Density functional theory study on B30N20 nanocage in structural properties and thermochemical outlook. Fullerenes, Nanotubes and Carbon Nanostructures 2013, 21, 503-515, https://doi.org/10.1080/1536383X.2011.629762.

61. Monajjemi, M.; Ghiasi, R.; Ketabi, S.; Passdar, H.; Mollaamin, F. A Theoretical Study of Metal-Stabilised Rare Tautomers Stability: N4 Metalated Cytosine $\left(\mathrm{M}=\mathrm{Be}^{2+}, \mathrm{Mg}^{2+}, \mathrm{Ca}^{2+}, \mathrm{Sr}^{2+}\right.$ and $\left.\mathrm{Ba}^{2+}\right)$ in Gas Phase and Different Solvents. Journal of Chemical Research 2004, 1, 11-18, https://doi.org/ 10.3184/ 030823404323000648.

62. Monajjemi, M.; Baheri, H.; Mollaamin, F. A percolation model for carbon nanotube-polymer composites using the Mandelbrot-Given curve, Journal of Structural Chemistry 2011, 52, 54-59, https://doi.org/ 10.1134/ S0022476611010070.

63. Mahdavian, L., Monajjemi, M. Alcohol sensors based on SWNT as chemical sensors: Monte Carlo and Langevin dynamics simulation , Microelectronics Journal, 2010, 41(2-3), 142-149, 10.1016/ j.mejo. 2010.01.011.

64. Monajjemi, M., Heshmat, M., Haeri, H.H., Kaveh, F ,Theoretical study of vitamin properties from combined QM-MM methods: Comparison of chemical shifts and energy, Russian Journal of Physical Chemistry A, 2006, 80(7), 1061-1068, 10.1134/S0036024406070119. 
65. Monajjemi, M., Afsharnezhad, S., Jaafari, M.R., ...Mollaamin, F., Monajemi, H, Investigation of energy and NMR isotropic shift on the internal rotation Barrier of $\Theta_{4}$ dihedral angle of the DLPC: A GIAO study, Chemistry, 2008, 17(1), 55-69

66. Mollaamin, F., Monajjemi, M. Harmonic linear combination and normal mode analysis of semiconductor nanotubes vibrations Journal of Computational and Theoretical Nanoscience, 2015, 12(6), pp. 1030-1039, 10.1166/jctn.2015.3846

67. Lu, R.; Zhao, X.; Li, J.; Niu, P.; Yang, B.; Wu, H.; Wang, W.; Song, H.; Huang, B.; Zhu, N.; et al. Articles Genomic characterisation and epidemiology of 2019 novel coronavirus: implications for virus origins and receptor binding. The Lancet 2020, 395, 565-574, https://doi.org/10.1016/S0140-6736(20)30251-8.

68. Walls, A.C.; Park, Y-J.; Tortorici, M.A.; Wall, A.; McGuire, A.T.; Veesler, D. Structure, Function, and Antigenicity of the SARS-CoV-2 Spike Glycoprotein. Cell 2020, 181, 281-292, 10.1016/j.cell.2020.02.058.

69. Zheng, M.; Song, L. Novel antibody epitopes dominate the antigenicity of spike glycoprotein in SARS-CoV2 compared to SARS-CoV. Cell. Mol. Immunol. 2020, 17, 536-538, 10.1038/s41423-020-0385-z.

70. Yuan, M.; Wu, N.C.; Zhu, X.; Lee, C.C.D.; So, R.T.Y.; Lv, H.; Mok, C.K.P.; Wilson, I.A. A highly conserved cryptic epitope in the receptor binding domains of SARS-CoV-2 and SARS-CoV. Science 2020, 368, 630633, https://doi.org/10.1126/science.abb7269.

71. Rahman, N.; Basharat, Z.; Yousuf, M.; Castaldo, G.; Rastrelli, L. Virtual Screening of Natural Products Against Type II Transmembrane Serine Protease (TMPRSS2), the Priming Agent of Coronavirus 2 (SARSCoV-2). Molecules 2020, 25, 2271, https://doi.org/10.3390/molecules25102271.

72. Rahman, N.; Ajmal, A.; Ali, F.; Rastrelli, L. Core proteome mediated therapeutic target mining and multi-epitope vaccine design for Helicobacter pylori. Genomics 2020, 112, 3473-3483, https://doi.org/10.1016/j.ygeno.2020.06.026.

73. Thanh Le, T.; Andreadakis, Z.; Kumar, A.; Gómez Román, R.; Tollefsen, S.; Saville, M.; Mayhew, S. The COVID-19 vaccine development landscape. Nat. Rev. Drug Discov. 2020, 19, 305-306, https://doi.org/10.1038/d41573-020-00073-5. 